\title{
Detecting Drought Variability by using Two-Dimensional Correlation Analysis
}

\author{
Fatih DIKBAŞ ${ }^{1}$ \\ Ülker Güner BACANLI²
}

\begin{abstract}
The Standardized Precipitation Index (SPI) has been recognized as the standard index that should be used for quantifying and reporting meteorological drought. This study aims to present the application of the two-dimensional correlation method for determining the spatial and temporal variability of drought among the SPI series. Heatmaps were used as a new way of visualizing SPI series which enables visual inspection of dry and wet periods. The developed method was applied on 13 meteorological stations in Central Anatolia. Significant variations in drought behaviour were found in the investigated region even for the stations close to each other.
\end{abstract}

Keywords: Drought variability, standardized precipitation index, two-dimensional correlation, drought visualization, Central Anatolia.

\section{INTRODUCTION}

Drought is an extreme natural weather event posing a threat to available water resources and it has been associated with human-induced global warming [1]. Together with the slow but continuous worldwide decrease of total available water [2, 3] and rapidly rising human population, the intensity and frequency of drought events is likely to increase worldwide. Droughts can cause devastating impacts on the environment and on society resulting with higher economic damages than the other catastrophes like earthquakes. Droughts influence both surface water and groundwater resources, therefore, drought modelling has drawn attention of researchers in many fields including ecology, hydrology, meteorology and agriculture [4]. The current research shows that drought will continue to be one of the most important natural disasters faced by the future generations. This increasing threat of extreme weather events also increases the requirement for reliable modelling, estimation and prediction of drought. Accurate evaluation of the existing data on drought allows us to

\footnotetext{
Note: January 7, 2020.

- Discussions on this paper will be accepted by September 30, 2021.

- https://doi.org/10.18400/tekderg.559195

1 Pamukkale University, Civil Engineering Department, Denizli, Turkey

f_dikbas@pau.edu.tr - https://orcid.org/0000-0001-5779-2801

2 Pamukkale University, Civil Engineering Department, Denizli, Turkey ugbacanli@pau.edu.tr - https://orcid.org/0000-0002-2279-9138
}

- This paper has been received on April 30, 2019 and accepted for publication by the Editorial Board on 
monitor and predict changing drought patterns in spatial and temporal scales. There is a continuous research to understand the behavior of droughts under climate change due to the changes in spatio-temporal variability of precipitation [4].

Drought contrasts from other natural hazards in that it is difficult to determine the initiation and the end of drought. The effects of drought are seen in many areas including economic, social, and environmental processes. Drought has been classified into four groups: socioeconomic, agricultural, hydrological and meteorological [5]. Generally, the first observed drought is the meteorological (or climatological) drought, later the effects of agricultural drought are seen. Socio-economic drought occurs either together with or after meteorological drought if water supply does not satisfy water demand.

Determination of drought is also a difficult task. Different drought parameters were proposed by researchers in order to define drought as well as to identify the interactions between drought and hydrological/meteorological events (e.g. the Rainfall Anomaly Index (RAI) [6], the Crop Moisture Index (CMI) [7], the Standardized Precipitation Index (SPI) [8], the Surface Water Supply Index (SWSI) [9], the Percent of Normal Precipitation Index (PNPI) [10] and the Standardized Precipitation-Evapotranspiration Index (SPEI) [11].

With the aim of detecting, observing and analysing drought events, the SPI has been widely used by researchers as a well-reviewed and robust index since it has a clear computation procedure and a multi-scalar character. The calculation of the SPI, the drought index recommended by the World Meteorological Organisation, requires only the precipitation data as input [12].

The following are some examples in current literature applying SPI together with other methods aiming at identification of drought. A comparison of SPI and Palmer Drought Severity Index (PDSI) was presented by Guttmann [13]. Drought in the south-western United States was examined using the SPI by Hayes et al. [14]. Keyantash and Dracup [15] used 14 drought indices in United States. Morid et al. [16] used seven meteorological indices which included the Percent of Normal (PN), the Deciles Index (DI), the China-Z index (CZI), the SPI, the Modified CZI (MCZI), the Z-Score and the Effective Drought Index (EDI) for the assessment of drought in Iran. Livada and Assimakopoulos [17] calculated the SPI values by utilising data from 23 stations in Greece. They investigated drought's intensity and duration for a period of 51 years.

A comparison of the Reconnaissance Drought Index (RDI) and SPI was carried out in Iran by Jamshidi et al. [18]. A study by Jain et al. [19] compared SPI, Statistical Z-Score, EDI, Rainfall Departure (RD), CZI, and Rainfall Decile based Drought Index (RDDI) in central India. Bandyopadhyay and Saha used four drought indices (SPI, RAI, Normalized Difference Vegetation Index (NDVI) Anomaly Index (NAI) and Vegetation Condition Index (VCI)) for the analysis of drought in India [20].

The previous works generally make use of time series graphs for investigating SPI values. This paper presents a new approach where matrices and heatmaps are evaluated for revealing temporal and spatial relationships among SPI series. This approach allows visual and quantitative comparison of SPI series with different durations and also provides information on differences of drought behaviour among stations. 


\subsection{Drought in Turkey}

In a climatological viewpoint, the majority of Turkish mainland has a dry and semi-dry property and influence of drought has been frequently experienced in the region throughout history [21]. Even though drought is a serious problem and the severe drought in 1876 had killed about 200.000 people $[21,22]$, there is a limited number of scientific studies on drought in Turkey. Some of the existing research were focused on water supply system and drought in Istanbul [23]; analysis of spatial and temporal patterns [24] and probabilities [25] of drought in Turkey based on the SPI; application of meteorological drought modelling for drought in Turkey [26] and in Central Anatolia [27]; drought analysis in AntakyaKahramanmaraş Graben [28]; analysis of the 2007 and 2013 droughts in Turkey by NOAH Hydrological Model [29], trend analysis of precipitation and drought in the Aegean region [30] and long-term spatio-temporal drought variability in Turkey [31, 32].

The drought document of the Turkish Ministry of Agriculture and Forestry states that drought occurs in connection with the irregularities in precipitation events [21]. Figure 1 shows that these significant precipitation variations cause droughts in different severity levels in widespread or local scales in Turkey which is within the Mediterranean macro climate zone in the subtropical belt [33]. The figure shows that Central Anatolia is the most vulnerable region in terms of drought. Therefore, the Central Anatolian Region was selected for the application of the two-dimensional correlation method [34] for a quantitative identification and comparison of temporal drought patterns among selected meteorological observation stations in the region.

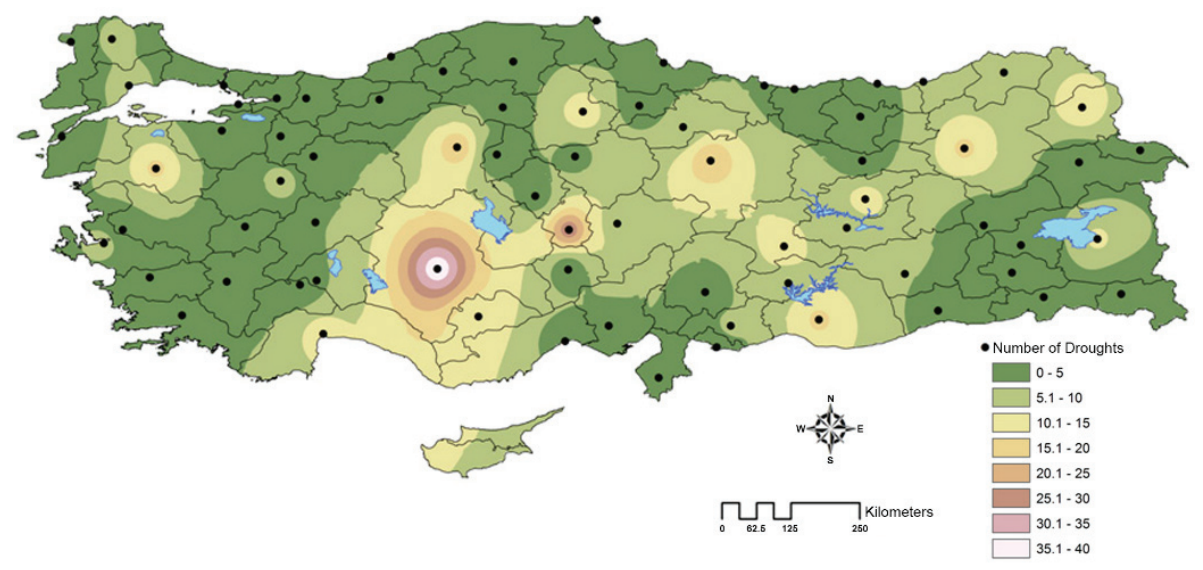

Figure 1 - Areal distribution of drought numbers in Turkey (1940-2010) [32]

\subsection{The Study Area and Available Data}

The Central Anatolian Region extends over an area of approximately $151.000 \mathrm{~km}^{2}$, which is the second largest region of Turkey. It consists of four subbasins (the upper Kizilirmak, the middle Kizilırmak, the upper Sakarya and the Konya basin) (Figure 2). Steppe climate prevails in the region [27, 35, 36]. In this study, precipitation observations from 13 meteorological stations in the Central Anatolian Region listed in Table 1 were used for meteorological drought analysis. 


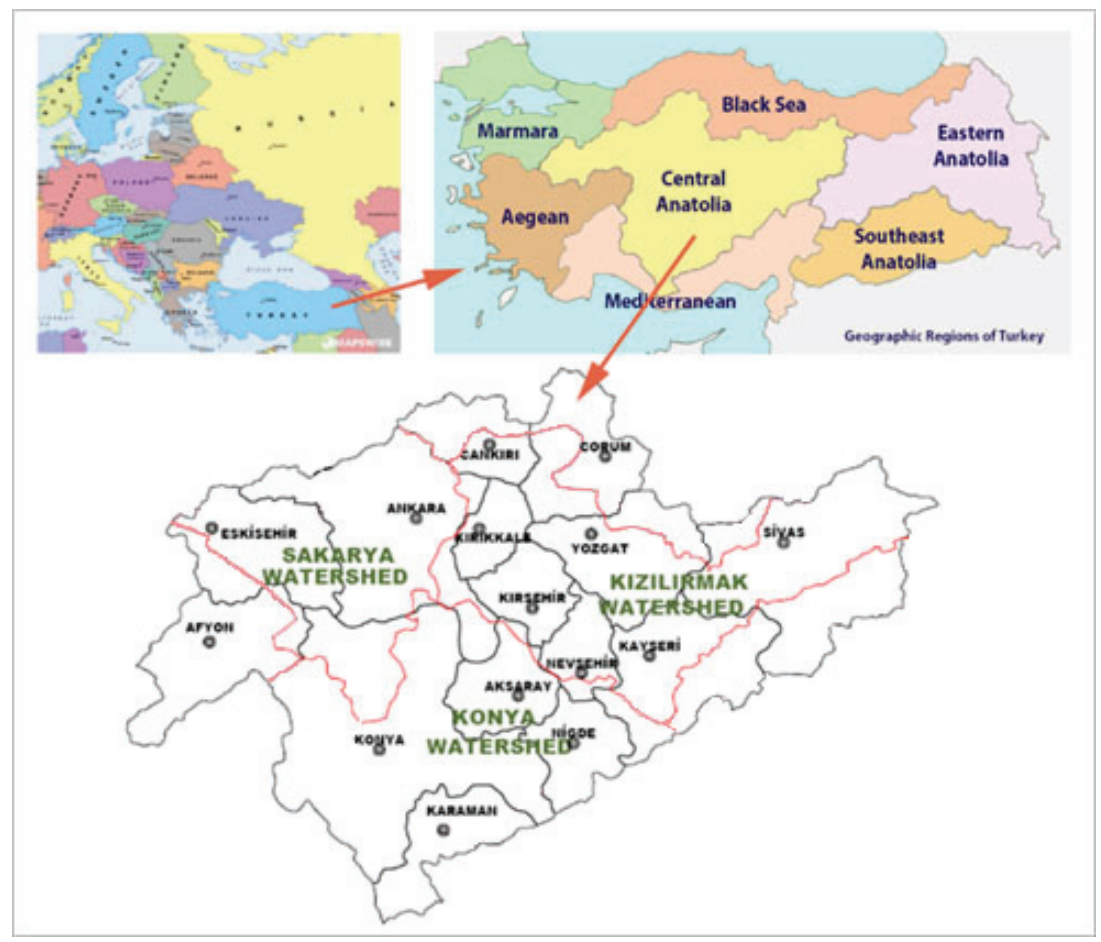

Figure 2 - Central Anatolian Region (adapted from [37])

Table 1 - Spatial characteristics of the investigated stations [37]

\begin{tabular}{|c|c|c|c|c|c|c|}
\hline Watershed & $\begin{array}{l}\text { Meteorological } \\
\text { Stations }\end{array}$ & $\begin{array}{c}\text { Meteorological } \\
\text { Station } \\
\text { Number }\end{array}$ & Longitude & Latitude & $\begin{array}{l}\text { Elevation } \\
\text { (m) }\end{array}$ & $\begin{array}{c}\text { Watershed } \\
\text { Area } \\
\left(\mathrm{km}^{2}\right)\end{array}$ \\
\hline \multirow{3}{*}{$\begin{array}{l}\text { Upper } \\
\text { Sakarya }\end{array}$} & Eskişehir & 17124 & $30^{\circ} 35^{\prime}$ & $39^{\circ} 47^{\prime}$ & 786 & \multirow{3}{*}{33.847} \\
\hline & Ankara & 17130 & $32^{\circ} 53^{\prime}$ & $39^{\circ} 57^{\prime}$ & 891 & \\
\hline & Çankırı & 17080 & $33^{\circ} 37^{\prime}$ & $40^{\circ} 37^{\prime}$ & 751 & \\
\hline \multirow{3}{*}{ Konya } & Konya & 17244 & $32^{\circ} 33^{\prime}$ & $37^{\circ} 59^{\prime}$ & 1031 & \multirow{3}{*}{53.850} \\
\hline & Aksaray & 17192 & $34^{\circ} 03^{\prime}$ & $38^{\circ} 23^{\prime}$ & 961 & \\
\hline & Karaman & 17246 & $33^{\circ} 13^{\prime}$ & $37^{\circ} 12^{\prime}$ & 1023 & \\
\hline $\begin{array}{c}\text { Upper } \\
\text { Kiz1lırmak } \\
\end{array}$ & Sivas & 17090 & $37^{\circ} 01^{\prime}$ & $39^{\circ} 45^{\prime}$ & 1285 & 6.607 \\
\hline \multirow{6}{*}{$\begin{array}{c}\text { Middle } \\
\text { K1zılırmak }\end{array}$} & Kayseri & 17196 & $35^{\circ} 29^{\prime}$ & $38^{\circ} 45^{\prime}$ & 1093 & \multirow{6}{*}{78.180} \\
\hline & Nevşehir & 17193 & $34^{\circ} 42^{\prime}$ & $38^{\circ} 37^{\prime}$ & 1260 & \\
\hline & Niğde & 17250 & $34^{\circ} 41^{\prime}$ & $37^{\circ} 58^{\prime}$ & 1211 & \\
\hline & Kırşehir & 17160 & $34^{\circ} 09^{\prime}$ & $39^{\circ} 10^{\prime}$ & 1007 & \\
\hline & Kırıkkale & 17135 & $33^{\circ} 31^{\prime}$ & $39^{\circ} 51^{\prime}$ & 751 & \\
\hline & Yozgat & 17140 & $34^{\circ} 48^{\prime}$ & $39^{\circ} 49^{\prime}$ & 1298 & \\
\hline
\end{tabular}


This study presents the application of the two-dimensional correlation method for determining the spatial and temporal variability of drought among the SPI series. For this aim, two-dimensional correlation analysis was performed on SPI-1, SPI-3, SPI-6, SPI-9, SPI12 and SPI-24 series which were calculated for all stations. The following chapter provides a short background information on the calculation of the SPI and the two-dimensional correlation coefficients. Then, the application of the SPI and the two-dimensional correlation methods on available data is described. Finally, the results and conclusions are presented together with some discussion on the new approaches and viewpoints on the investigation of drought variability enabled by the use of the presented methodology.

\section{METHODS}

\subsection{The Standardized Precipitation Index (SPI)}

The SPI was introduced by McKee et. al. [12] with the purpose of determining droughts by investigating precipitation data. The SPI is a drought index which is commonly used worldwide [14]. Researchers have been routinely calculating the SPI based on monthly precipitation totals for various durations including $1,3,6,12,18,24,36,48$, and 60 months [15]. The SPI is calculated as follows:

$S P I=\frac{x_{i}-\mu}{\sigma}$

where $\mathrm{x}_{\mathrm{i}}$ is precipitation, $\mu$ is the mean of precipitation and $\sigma$ is the standard deviation. Probability distribution function for data is calculated by fitting the gamma function [38]. The data sets are organized for various periods. Later, $\mathrm{x}$ is presumed as the monthly total precipitation in the investigated period of time. The gamma distribution function is first fitted to the data accumulated for various time scales. The probability density function of the gamma distribution is defined as:

$g(x)=\frac{1}{\beta^{\alpha} \Gamma(\alpha)} x^{\alpha-1} e^{x / \beta}$

for $\mathrm{x}>0$ where, $\mathrm{x}$ is the amount of precipitation and $\Gamma(\alpha)$ is the Gamma function. The following equations are used for calculating $\alpha$, the shape parameter, and $\beta$, the scale parameter.

$\alpha=\frac{1}{4 A}\left(1+\sqrt{1+\frac{4 A}{3}}\right)$

$\beta=\frac{\bar{x}}{\alpha}$

Here, $\bar{x}$ is the mean precipitation and $\mathrm{A}$ is given by:

$A=\ln (\bar{x})-\frac{\sum \ln (x)}{n}$ 
The following equation defines the cumulative probability distribution:

$G(x)=\int_{0}^{x} g(x) d x=\frac{1}{\beta^{\alpha} \Gamma(\alpha)} \int_{0}^{x} x^{\alpha-1} e^{-x / \beta} d x$

The gamma distribution is undefined when $\mathrm{x}=0$, and, when the probability of zero precipitation $\mathrm{q}=\mathrm{P}(\mathrm{x}=0)$ is positive, the cumulative probability is calculated as follows:

$H(x)=q+(1-q) \cdot G(x)$

The cumulative probability distribution is then transformed into the standard normal distribution to yield the SPI [32]. The following table shows the drought classification according to the ranges of the calculated SPI values.

Table 2 - The categories of the Standardized Precipitation Index [12] [39]

\begin{tabular}{cc}
\hline SPI index values & Drought Category \\
\hline$\geq 2$ & Extremely Wet (W4) \\
$1.50 \sim 1.99$ & Very Wet (W3) \\
$1.00 \sim 1.49$ & Moderately Wet (W2) \\
$0.99 \sim 0$ & Mildly Wet (W1) \\
$0 \sim-0.99$ & Mild Drought (D1) \\
$-1.00 \sim-1.49$ & Moderate Drought (D2) \\
$-1.50 \sim-1.99$ & Severe Drought (D3) \\
$\leq-2$ & Extreme Drought (D4) \\
\hline
\end{tabular}

\subsection{Two-dimensional Correlation}

The two-dimensional correlation method assesses associations between matrices in two directions by making use of the horizontal and the vertical covariances $[34,40]$. The approach is based on the idea that the values of a variable generally have different variances in the horizontal and vertical directions when placed on a matrix. Before giving the equations for the two-dimensional correlation, two-dimensional variance and two-dimensional covariance are defined for a better understanding of the methodology.

\subsubsection{Two-dimensional Variance}

Variance is the measure of the spread around the average. The following equations show the calculation of the horizontal and the vertical variance:

$\operatorname{Var}_{h}(A)=\frac{\sum m \sum n\left(A_{m n}-\overline{A_{m}}\right)^{2}}{m \times n}$ 
$\operatorname{Var}_{v}(A)=\frac{\sum_{m} \sum_{n}\left(A_{m n}-\overline{A_{n}}\right)^{2}}{m \times n}$

In the above equations the averages of the $\mathrm{m}^{\text {th }}$ row and the $\mathrm{n}^{\text {th }}$ column of the matrix $\mathrm{A}$ are indicated by $\overline{A_{m}}$ and $\overline{A_{n}}$ respectively.

When the column averages in the matrices are more scattered around the overall average, the horizontal variance takes high values and when the column averages are closer to the overall average, the horizontal variance decreases in value. The same situation is valid for the row averages when calculating the vertical variance.

\subsubsection{Two-dimensional Covariance}

The linear dependence among variables is calculated by covariance which is a quantitative indicator of the co-variation of the variables. In the calculation of two-dimensional correlation, the horizontal covariance provides a measure of how changes in the column averages of one matrix are associated with changes in the column averages of a second matrix. Correspondingly, the vertical covariance provides a similar information among the rows of the compared matrices. The association between the compared variables is generally expected to be high when the covariance takes higher values (positive covariance indicates direct relationship and negative covariance indicates inverse relationship). The horizontal and vertical covariances between scalar matrices A and B are defined by the following equations:

$$
\begin{aligned}
& \operatorname{Cov}_{h}(A, B)=\frac{\sum m \sum n\left(A_{m n}-\overline{A_{m}}\right)\left(B_{m n}-\overline{B_{m}}\right)}{m \times n} \\
& \operatorname{Cov}_{v}(A, B)=\frac{\sum m \sum n\left(A_{m n}-\overline{A_{n}}\right)\left(B_{m n}-\overline{B_{n}}\right)}{m \times n}
\end{aligned}
$$

In the above equations, $\overline{B_{m}}$ and $\overline{B_{n}}$ are the averages of the $\mathrm{m}^{\text {th }}$ row and the $\mathrm{n}^{\text {th }}$ column of the matrix $\mathrm{B}$ respectively.

\subsubsection{Two-dimensional Correlation}

Covariance is a scale dependent measure of the joint variability among variables. The covariance is positive when the higher values of a variable correspond to the higher values of the compared variable and the same behavior is observed between the lower values of the variables. Covariance takes negative values when the values of the variables tend to show inverse relationship (i.e., higher values of a variable correspond to the lower values of the compared variable). The value of covariance is influenced with the magnitudes of the compared variables, therefore, its value has to be normalized when there is need for comparison of associations among multiple variable pairs. For example, it would not be reasonable to make comparisons of precipitation series by only using covariance because generally there are significant differences between scales of the observed precipitation series in different basins of varied climate zones. Correlation coefficient, which should be preferred in comparisons of variables, is the scaled and normalized version of covariance and it is 
dimensionless. Based on the horizontal and the vertical covariance values, the horizontal and vertical correlation coefficients are obtained with the following equations:

$$
\begin{aligned}
& r_{h}=\frac{\operatorname{Cov}_{h}(A, B)}{\sqrt{\operatorname{Var}_{h}(A) \operatorname{Var}_{h}(B)}} \\
& r_{v}=\frac{\operatorname{Cov}_{v}(A, B)}{\sqrt{\operatorname{Var}_{v}(A) \operatorname{Var}_{v}(B)}}
\end{aligned}
$$

The horizontal and the vertical correlations might also be calculated directly as follows:

$$
\begin{aligned}
& r_{h}=\frac{\sum_{m} \sum_{n}\left(A_{m n}-\overline{A_{m}}\right)\left(B_{m n}-\overline{B_{m}}\right)}{\sqrt{\left[\sum_{m} \sum_{n}\left(A_{m n}-\overline{A_{m}}\right)^{2}\right]\left[\sum_{m} \sum_{n}\left(B_{m n}-\overline{B_{m}}\right)^{2}\right]}} \\
& r_{v}=\frac{\sum_{m} \sum_{n}\left(A_{m n}-\overline{A_{n}}\right)\left(B_{m n}-\overline{B_{n}}\right)}{\sqrt{\left[\sum m \sum n\left(A_{m n}-\overline{A_{n}}\right)^{2}\right]\left[\sum_{m} \sum_{n}\left(B_{m n}-\overline{B_{n}}\right)^{2}\right]}}
\end{aligned}
$$

In the above equations, $\mathrm{r}_{\mathrm{h}}$ and $\mathrm{r}_{\mathrm{v}}$ are the horizontal and the vertical correlations between the matrices $\mathrm{A}$ and $\mathrm{B}$.

The two-dimensional correlation coefficients provide a quantitative measure of association between rows and columns of the compared matrices. Here in this paper, the SPI values obtained for each month of year are located in rows to generate the SPI matrices for all 13 stations. Then, the two-dimensional correlation coefficients are obtained for each year for each station allowing a quantitative comparison between both the annual drought characteristics of the stations and the differences between the SPI series when different durations are considered (1, 3, 6, 9, 12 and 24 months). For example, it is expected that the SPI series will have different annual averages when the investigated duration varies and quantitative evaluation of these differences will provide information on differences in drought behavior among the stations. The two-dimensional correlation method provides tools for making this deterministic comparison. The details of this process are presented below in Section 4.

\section{RESULTS AND DISCUSSION}

\subsection{The Standardized Precipitation Index (SPI) Analysis}

SPI values were computed for the 13 stations in the Central Anatolian Region, for the periods of 1, 3, 6, 9, 12 and 24 months, covering the years 1959-2001 (43 years). As an example, the relative frequencies of the SPI values calculated for the Çankırı station for the 1, 3, 6, 9, 12 and 24 months time periods are given in Figure 3. Extreme, severe and moderate droughts were identified in the basin. Relative frequencies were also calculated. The results obtained for all stations are displayed in Table 3.

The results of the SPI analysis indicated that a significant change could not be observed according to the ratios of the dry, normal or wet periods of a single station. However, normal (mild wet) or mild droughts were more frequently encountered in shorter periods (3-6 months) whereas severe and very severe droughts were observed during longer time periods 
(12-24 months) in the Central Anatolian Region. Both cases can be evaluated in a different view for various water resources problems. For instance, a drought with a 3 months duration might have more influence on soil moisture, while underground water resources might be influenced by a drought with a longer duration. The dryness ratios of the stations under investigation in the Central Anatolian Region were determined to vary between $55 \%$ and $20 \%$, and the wetness ratios were found to vary between $19 \%$ and $13 \%$ based on their SPI indices.

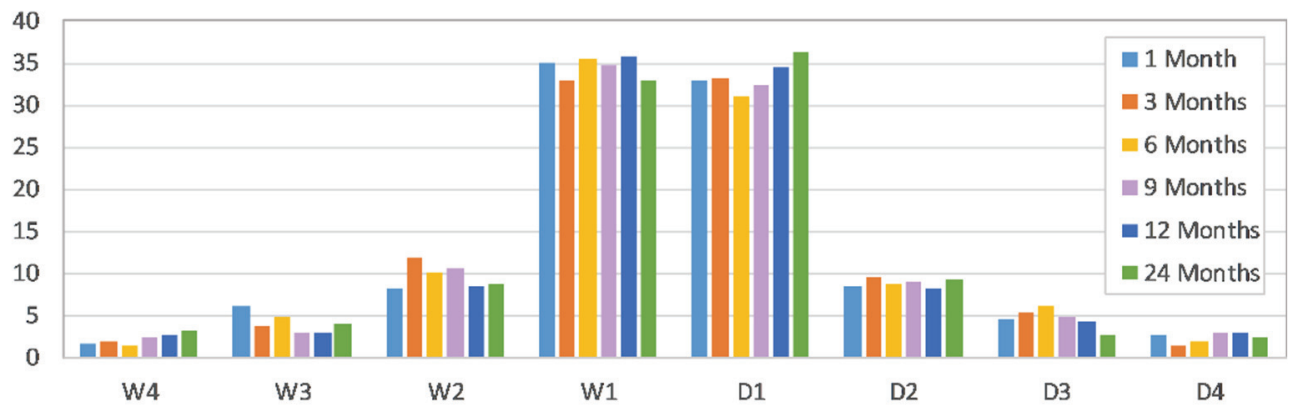

Figure 3 - Relative frequencies of SPI for the Çankırı Station

Table 3 - The dryness (D) and wetness (W) ratios (\%) of the SPI values of the evaluated stations in the Central Anatolian Region for time periods of 3, 6, 9, 12 and 24 months

\begin{tabular}{|c|c|c|c|c|c|c|c|c|c|c|c|}
\hline & \multirow{2}{*}{\multicolumn{2}{|c|}{3 Months }} & \multirow{2}{*}{\multicolumn{2}{|c|}{6 Months }} & \multirow{2}{*}{\multicolumn{2}{|c|}{9 Months }} & \multirow{2}{*}{\multicolumn{2}{|c|}{12 Months }} & \multirow{2}{*}{\multicolumn{2}{|c|}{24 Months }} \\
\hline & & & & & & & & & & & \\
\hline & & D & $\mathbf{W}$ & D & $\mathbf{W}$ & D & $\mathbf{W}$ & D & $\mathbf{W}$ & D & $\mathbf{W}$ \\
\hline \multirow{3}{*}{ Upper Sakarya } & Eskişehir & 47 & 16 & 44 & 18 & 44 & 16 & 41 & 15 & 44 & 16 \\
\hline & Ankara & 50 & 17 & 51 & 16 & 50 & 16 & 51 & 16 & 52 & 15 \\
\hline & Çankırı & 50 & 18 & 48 & 16 & 49 & 16 & 50 & 14 & 51 & 16 \\
\hline \multirow{3}{*}{ Konya } & Konya & 45 & 15 & 46 & 14 & 48 & 16 & 50 & 14 & 46 & 13 \\
\hline & Aksaray & 48 & 16 & 50 & 17 & 53 & 18 & 52 & 17 & 53 & 16 \\
\hline & Karaman & 49 & 17 & 46 & 16 & 46 & 16 & 48 & 15 & 54 & 16 \\
\hline $\begin{array}{c}\text { Upper } \\
\text { Kizılırmak }\end{array}$ & Sivas & 45 & 16 & 48 & 16 & 51 & 18 & 50 & 17 & 20 & 18 \\
\hline \multirow{8}{*}{$\begin{array}{c}\text { Middle } \\
\text { Kizılırmak }\end{array}$} & Kayseri & 50 & 16 & 50 & 17 & 50 & 16 & 50 & 16 & 55 & 18 \\
\hline & Nevşehir & 46 & 16 & 50 & 16 & 47 & 16 & 46 & 16 & 51 & 16 \\
\hline & Niğde & 45 & 17 & 44 & 15 & 46 & 16 & 48 & 15 & 47 & 14 \\
\hline & Kırşehir & 46 & 17 & 48 & 16 & 49 & 18 & 52 & 18 & 47 & 19 \\
\hline & Kırıkkale & 49 & 17 & 49 & 15 & 54 & 17 & 55 & 17 & 52 & 18 \\
\hline & Yozgat & 48 & 15 & 46 & 17 & 48 & 16 & 48 & 15 & 20 & 16 \\
\hline & Average & 48 & 16 & 48 & 16 & 49 & 17 & 49 & 16 & 46 & 16 \\
\hline & Range & $45-50$ & $15-18$ & $44-51$ & $14-18$ & $44-54$ & $16-18$ & $41-55$ & $14-18$ & $20-55$ & $13-19$ \\
\hline
\end{tabular}


It was observed that the maximum drought duration increased with the increase of the period. Moreover, when the droughts in the Central Anatolian Region are examined, it has been determined that the duration of droughts tend to increase. Three months SPI indicated a 13 months of drought duration, while 24 months SPI indicated a 72 months of drought duration. After the determination of the SPI values for each station for each period, the degree of relationship between the obtained SPI series were assessed by applying the two-dimensional correlation method. The assessment is made both in terms of the SPI values of each month for each year and in terms of the calculated durations (1-24 months) as explained below.

\subsection{Two-dimensional Correlation Analysis}

For calculating the horizontal and vertical correlations between each station for each year, all calculated SPI series were located on matrices for each station as shown in the heatmaps generated by using the SPI series of Ankara and Çankırı stations (Figure 4). In the heatmaps, the columns for each year start with January and end with December. Ankara and Çankırı stations were selected to introduce the application of the two-dimensional correlation analysis on SPI series. The heatmaps for the remaining 11 stations are presented in the Appendix. As far as the authors know, this representation is used for the first time in literature for the inspection of SPI series and enables a visual evaluation of drought variation both with time and with the variation of investigated period. The darker shades of red indicate the periods with a higher intensity of drought and alternatively, the darker shades of blue indicate the wet periods. Visual comparison of the SPI temporal variability heatmaps of different stations also provides clues about the existence, duration and severity of concurrent droughts. For example, the heatmaps in the Appendix show that a very wet period is observed for most of the cities in the years 1996 and 1997; while a persistent drought was observed in Eskişehir in the same years it was neither dry nor wet in Aksaray in these years.

Calculation of the two-dimensional correlations between the SPI matrices of different stations provides an opportunity to make a quantitative comparison of associations between the variation of the SPI values both with time and with the evaluated period $(1,3,6,9,12$ and 24 months). The two-dimensional Pearson's correlations calculated between the whole SPI matrices of all station pairs present an overall evaluation of the degrees of associations (Figure 5). For a better discrimination of higher and lower associations, this figure uses tones of red for indicating lower values and tones of green for indicating higher values. The stations in Ankara and Çankırı have the highest correlation (0.740) followed by the station pairs Çankırı-Kırıkkale (0.735) and Kayseri-Nevşehir (0.725). These relatively higher correlations point out that drought shows a similar behavior among the stations. Alternatively, the lower correlated pairs might have more significant differences in view of drought behavior. For example, the correlation values obtained for Eskişehir are all close to zero which might indicate that drought variability in Eskişehir has no significant association with the compared stations.

Another finding based on the results in Figure 5 is that there are two groups of stations highly correlated with each other but having lower correlations with the remaining stations. The first group is Ankara, Çankırı, Kırıkkale and Kırşehir stations which are located in the upper section of the region and the correlations between these stations vary between 0.531 and 0.740. The other highly correlated group includes the stations Kayseri, Nevşehir, Niğde, 
Sivas and Yozgat, which are in the eastern part of the region. The correlations for the second group varies between 0.588 and 0.725 .

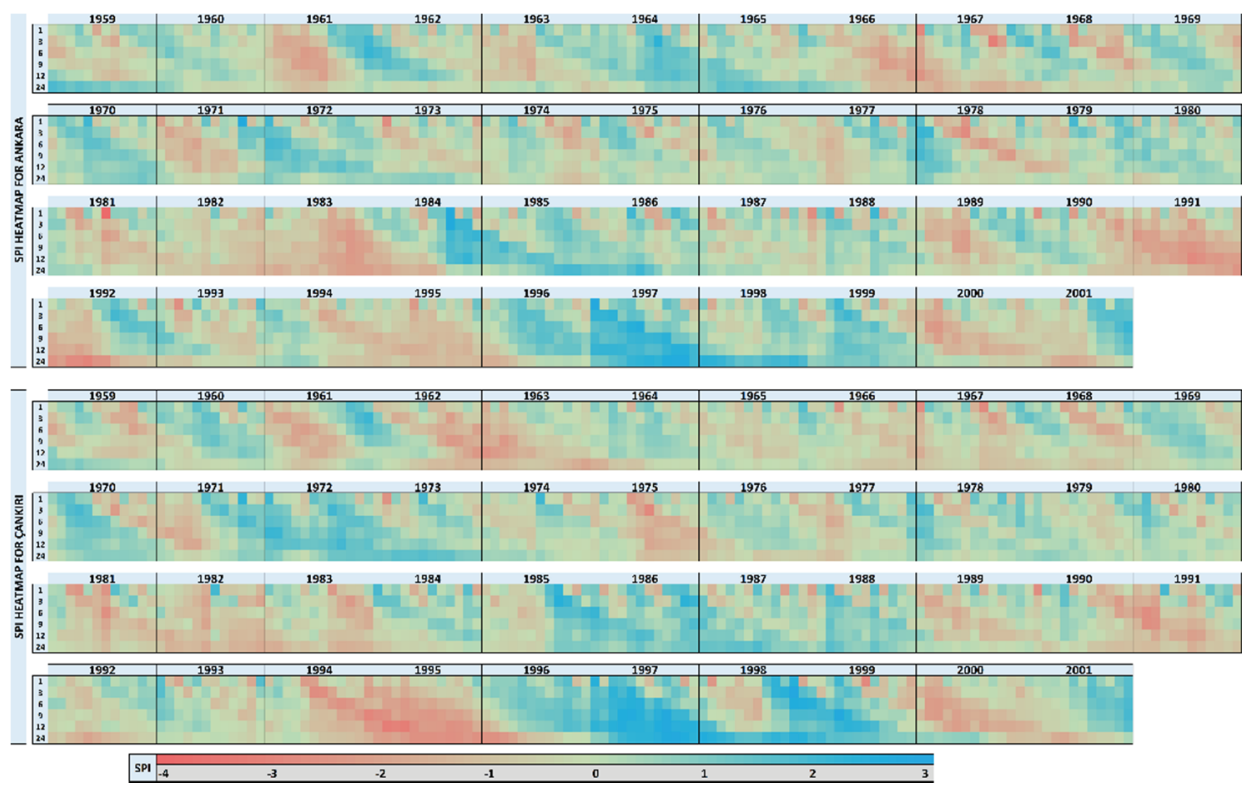

Figure 4 - SPI matrices for Ankara (top) and Çankırl (bottom) stations showing temporal variability of drought

\begin{tabular}{|c|c|c|c|c|c|c|c|c|c|c|c|c|}
\hline & Ankara & Çankırı & Eskişehir & Karaman & Kayseri & Kırıkkale & Kırşehir & Konya & Nevşehi & Niğde & Sivas & Yozgat \\
\hline Aksaray & 0,033 & 0,014 & 0,063 & 0,099 & 0,135 & $-0,026$ & 0,058 & 0,059 & 0,135 & $-0,003$ & 0,049 & 0,023 \\
\hline Ankara & & 0,740 & $-0,014$ & 0,215 & 0,237 & 0,715 & 0,604 & 0,176 & 0,286 & 0,252 & 0,280 & 0,309 \\
\hline Çankırı & & & $-0,086$ & 0,075 & 0,202 & 0,735 & 0,531 & 0,042 & 0,215 & 0,219 & 0,229 & 0,301 \\
\hline Eskişehir & & & & 0,113 & $-0,024$ & $-0,025$ & $-0,010$ & 0,126 & $-0,115$ & $-0,115$ & 0,007 & $-0,083$ \\
\hline Karaman & & & & & 0,448 & 0,154 & 0,249 & 0,625 & 0,464 & 0,532 & 0,468 & 0,403 \\
\hline Kayseri & & & & & & 0,289 & 0,279 & 0,407 & 0,725 & 0,670 & 0,691 & 0,588 \\
\hline Kırıkkale & & & & & & & 0,634 & 0,125 & 0,306 & 0,245 & 0,265 & 0,341 \\
\hline Kırşehir & & & & & & & & 0,160 & 0,368 & 0,302 & 0,287 & 0,341 \\
\hline Konya & & & & & & & & & 0,468 & 0,600 & 0,463 & 0,474 \\
\hline Nevşehir & & & & & & & & & & 0,652 & 0,679 & 0,647 \\
\hline Niğde & & & & & & & & & & & 0,667 & 0,627 \\
\hline Sivas & & & & & & & & & & & & 0,602 \\
\hline
\end{tabular}

Figure 5 - Two-dimensional Pearson's correlations between the SPI matrices of the stations

The behavior of drought might show variations with the progress of time even though there is a relatively high correlation between the SPI values of the stations. For example, the heatmaps for Ankara and Çankırı show that drought was more severe in Ankara in 1992 while it was more severe in Çankırı in 1994-1995 period. Therefore, calculation of correlations at annual scale enables determination of the differences between the variations of drought behavior through the investigated duration for the compared stations. Figure 6 shows the two- 
dimensional Pearson's correlations ( $\mathrm{r}$ ), the horizontal correlations $\left(\mathrm{r}_{\mathrm{h}}\right)$ and the vertical correlations $\left(\mathrm{r}_{\mathrm{v}}\right)$ between the SPI matrices of the Ankara and Çankırı stations for each year in the investigated period. This figure also uses tones of red for indicating lower values and tones of green for indicating higher values.

\begin{tabular}{|c|c|c|c|c|c|c|c|c|c|c|c|c|c|c|c|}
\hline Year & 1959 & 1960 & 1961 & 1962 & 1963 & 1964 & 1965 & 1966 & 1967 & 1968 & 1969 & 1970 & 1971 & 1972 & 1973 \\
\hline$r$ & 0,503 & 0,017 & 0,882 & 0,311 & $-0,097$ & 0,681 & 0,640 & 0,452 & 0,616 & 0,602 & 0,474 & 0,397 & 0,666 & 0,538 & 0,142 \\
\hline$r_{h}$ & 0,549 & $-0,059$ & 0,813 & 0,408 & 0,162 & 0,557 & 0,6 & 0,594 & 0,565 & 0,558 & 0,675 & 401 & 736 & 516 & 0,011 \\
\hline$r_{v}$ & 0,416 & 0,151 & 0,886 & 0,378 & $-0,195$ & 0,757 & 0,698 & 0,412 & 0,765 & 0,661 & 0,469 & 0,417 &, 629 & 0,635 &, 150 \\
\hline Year & 1974 & 1975 & 1976 & 1977 & 1978 & 1979 & 1980 & 1981 & 1982 & 1983 & 1984 & 1985 & 1986 & 1987 & 1988 \\
\hline$r$ & 0,728 & 0,609 & 0,396 & $-0,356$ & 0,754 & 0,622 & 0,436 & 0,678 & 0,595 & 0,708 & 0,885 & 0,735 & 0,442 & 0,567 & 0,514 \\
\hline$r_{h}$ & 0,725 & 0,619 & 0,594 & $-0,322$ & 0,675 & 0,570 & 0,441 & 0,578 & 0,479 & 0,625 & 0,902 & 0,732 & 0,583 & 0,581 & 0,442 \\
\hline$r_{v}$ & 0,737 & 0,626 & 0,410 & $-0,324$ & 0,792 & 0,579 & 0,512 & 0,752 & 0,708 & 0,709 & 0,854 & 0,695 & 0,390 & 0,645 & 0,570 \\
\hline Year & 1989 & 1990 & 1991 & 1992 & 1993 & 1994 & 1995 & 1996 & 1997 & 1998 & 1999 & 2000 & 2001 & & \\
\hline$r$ & 0,863 & 0,328 & 0,743 & 0,898 & 0,712 & 0,279 & 0,609 & 0,844 & 0,849 & 0,841 & 0,790 & 0,599 & 0,752 & & \\
\hline$r_{h}$ & 0,846 & 0,348 & 0,751 & 0,917 & 0,737 & 0,234 & 0,693 & 0,846 & 0,865 & 0,876 & 0,753 & 0,756 & 0,762 & & \\
\hline$r_{v}$ & 0,860 & 0,487 & 0,733 & 0,834 & 0,736 & 0,321 & 0,462 & 0,803 & 0,769 & 0,754 & 0,771 & 0,424 & 0,669 & & \\
\hline
\end{tabular}

Figure 6 - Two-dimensional Pearson's correlations $(r)$, horizontal correlations $\left(r_{h}\right)$ and vertical correlations $\left(r_{v}\right)$ between the annual SPI matrices of the Ankara and Çankur stations

An overall inspection of the heatmaps and Figure 6 reveals that the SPI matrices are generally not highly correlated except for a few years including 1961, 1984, 1989 and the 1996-1998 period. It is also seen that there is an inverse relationship between the monthly SPI series for the compared stations in $1977\left(\mathrm{r}_{\mathrm{v}}=-0.324\right)$ and that the SPI-1, SPI-3, SPI-6, SPI-9, SPI-12 and SPI-24 series are also inversely related in $1977\left(\mathrm{r}_{\mathrm{h}}=-0.322\right)$. This inverse relationship is also validated by the Pearson's correlation for the same year $(\mathrm{r}=-0.356)$.

The highest $r(0.898)$ and $r_{h}(0.917)$ values were obtained for 1992 while the highest $r_{v}(0.886)$ was obtained for 1961, all of which are much higher than the correlation between the whole matrices (0.740). All correlations for 1977 are negative (and minimum) indicating an inverse relationship both in the vertical and the horizontal directions. For some years, there are significant differences between the values of $r, r_{h}$ and $r_{v}$. For example, in the year $2000, r_{h}=$ 0.756 and $r_{v}=0.424$, indicating that the row-wise relationship of SPI values are stronger and that the column-wise relationship is weaker than the association indicated by the Pearson's correlation. Alternatively, in 1982, the row-wise relationship is weaker $\left(r_{h}=0.479\right)$ and the column-wise relationship $\left(\mathrm{r}_{\mathrm{v}}=0.708\right)$ between the SPI values are stronger. Similar situations are observed in years like 1993, 1967 and 1995 in which a severe drought was observed in both stations as also seen in the heatmaps. The correlation values in Figure 6 provide a clear picture of the variation of the behavior of drought from 1959 to 2001 and show that there are periods where the relationship is strong and there are periods where the relationship is weak or even inverse. This situation was also observed in other stations indicating a strong temporal and spatial variation of drought behavior in the region.

The correlation calculations were made for a total of 77 station pairs, but they are not presented here because of space restrictions and can be downloaded from the following link:

https://drive.google.com/open?id=1soOtBWN5dcDQ_QPR1hyYygF_4YJPVVyU 
The results for other stations point out that there are significant variations in drought behavior through the investigated period and the variations do not follow a similar trend. The obtained results show that the behavior of drought might show significant differences when investigated annually even though the compared stations are spatially close to each other and even their SPI series are highly correlated. For example, the stations in Kayseri and Nevşehir are very close to each other but through the investigated period of 43 years the correlations were higher than 0.9 for only 3 years $(1976,1996$ and 1998). The average annual correlation for this pair is 0.67 , and in some years $(1960,1990$ and 1994) the correlations fall under 0.3 . The correlations do not show a stable behavior in any of the station pairs. Under the light of the findings of this study, future works might aim at determination of drought frequency and variation of drought severity by evaluating more recent data.

\subsection{The 2DCorr Software}

The software used for the application of the presented methodology was developed in the Visual Studio environment with Visual Basic. The software is an adapted version of the Corr2D software and accepts SPI data matrices as input. The software will be provided freely by the authors upon request together with sample input and output files.

\section{CONCLUSIONS}

In this study, SPI values were calculated by using monthly precipitation values of 13 stations in the Central Anatolian Region. Two-dimensional correlations were calculated between the station pairs for investigating variability of drought according to both the annual relationships and the evaluated period (1, 3, 6, 9, 12 and 24 months). The drought periods in the region have shown a cyclic behavior as indicated by the long term observation data. Furthermore, the two-dimensional correlation results have shown that the drought behavior exhibits significant variations even for the station pairs which are highly correlated.

The two-dimensional correlation method provides an in-depth evaluation of the SPI series. The main conclusion of the study is that there are significant temporal and spatial variations in drought behavior in the investigated Central Anatolian Region which is regarded as the most vulnerable region for drought. The findings indicate that the presented approach might be reliably used in drought assessment and evaluation. Determination of regional variations in drought behavior has an important role in the planning and design of water structures. Therefore, knowledge of drought variability makes an important contribution in making decisions on drought precautions and provides possibilities for better predictions on future droughts.

\section{Symbols}

$\begin{array}{ll}\mathrm{x}_{\mathrm{i}} & : \text { Observed precipitation } \\ \mu & : \text { Mean precipitation } \\ \sigma & : \text { Standard deviation }\end{array}$




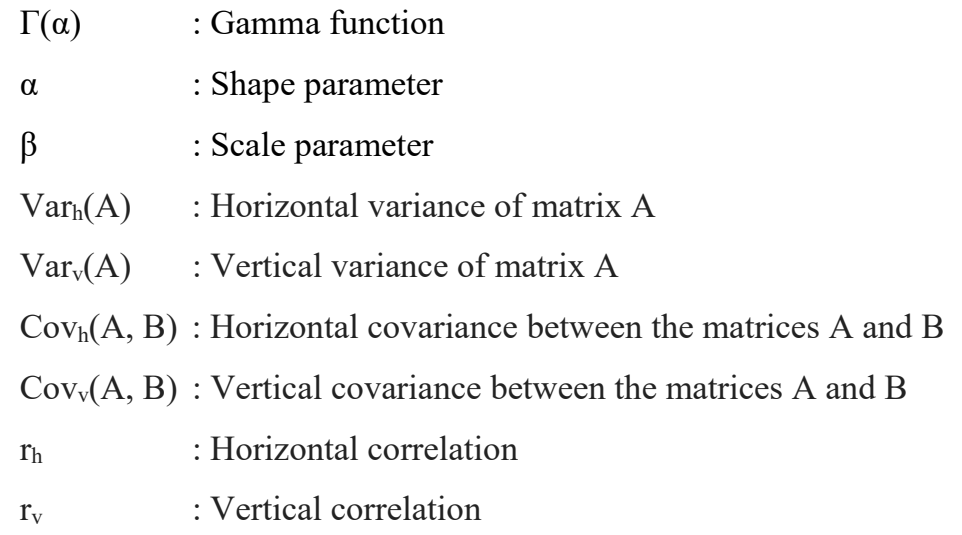

\section{References}

[1] Hansen, J., Sato, M., Ruedy, R., Lacis, A., Oinas, V., Global Warming in the TwentyFirst Century: An Alternative Scenario. Proc. Natl. Acad. Sci. U. S. A., 97(18), 98759880, 2000.

[2] Leconte, J., Forget, F., Charnay, B., Wordsworth, R., Pottier, A., Increased Insolation Threshold for Runaway Greenhouse Processes on Earth-Like Planets. Nature, 504(7479), 268-271, 2013.

[3] Popp, M., Schmidt, H., Marotzke, J., Transition to a Moist Greenhouse with Co2 and Solar Forcing. Nat Commun, 7, 2016.

[4] Mishra, A.K., Singh, V.P., A Review of Drought Concepts. Journal of Hydrology, 391(1), 202-216, 2010.

[5] Wilhite, D.A., Glantz, M.H., Understanding: The Drought Phenomenon: The Role of Definitions. Water International, 10(3), 111-120, 1985.

[6] Van Rooy, M.P., A Rainfall Anomaly Index Independent of Time and Space. Notos, 14, 43, 1965.

[7] Palmer, W.C., Keeping Track of Crop Moisture Conditions, Nationwide: The New Crop Moisture Index. Weatherwise, 21(4), 156-161, 1968.

[8] McKee, T.B.N., J. Doeskin, N., Kleist, J., Drought Monitoring with Multiple Time Scales. 1995.

[9] Shafer, B.A., Dezman, L.E., Development of a Surface Water Supply Index (Swsi) to Assess the Severity of Drought Conditions in Snowpack Runoff Areas, in 50th Annual Western Snow Conference. 1982, Western Snow Conference: Reno, Nevada.

[10] Willeke, G., Hosking, J., Wallis, J., Guttman, N., The National Drought Atlas. Institute for water resources report, 94, 1994. 
[11] Vicente-Serrano, S.M., Beguería, S., López-Moreno, J.I., A Multiscalar Drought Index Sensitive to Global Warming: The Standardized Precipitation Evapotranspiration Index. J. Clim., 23(7), 1696-1718, 2010.

[12] McKee, T.B., Doesken, N.J., Kleist, J., The Relationship of Drought Frequency and Duration to Time Scales, in $8^{\text {th }}$ Conference on Applied Climatology. 1993: Anaheim, CA, . p. 179-184.

[13] Guttman, N.B., Accepting the Standardized Precipitation Index: A Calculation Algorithm. Journal of the American Water Resources Association, 35(2), 311-322, 1999.

[14] Hayes, M., Svoboda, M., Wall, N., Widhalm, M., The Lincoln Declaration on Drought Indices: Universal Meteorological Drought Index Recommended. Bulletin of the American Meteorological Society, 92(4), 485-488, 2011.

[15] Keyantash, J., Dracup, J.A., The Quantification of Drought: An Evaluation of Drought Indices. Bulletin of the American Meteorological Society, 83(8), 1167-1180, 2002.

[16] Morid, S., Smakhtin, V., Moghaddasi, M., Comparison of Seven Meteorological Indices for Drought Monitoring in Iran. Int. J. Climatol., 26(7), 971-985, 2006.

[17] Livada, I., Assimakopoulos, V.D., Spatial and Temporal Analysis of Drought in Greece Using the Standardized Precipitation Index (Spi). Theoretical and Applied Climatology, 89(3-4), 143-153, 2007.

[18] Jamshidi, H., Khalili, D., Zadeh, M.R., Hosseinipour, E.Z. Assessment and Comparison of Spi and Rdi Meteorological Drought Indices in Selected Synoptic Stations of Iran. in World Environmental and Water Resources Congress 2011: Bearing Knowledge for Sustainability - Proceedings of the 2011 World Environmental and Water Resources Congress. 2011.

[19] Jain, V.K., Pandey, R.P., Jain, M.K., Comparison of Drought Indices for Appraisal of Drought Characteristics in the Ken River Basin. Weather and Climate Extremes, (8), 1 $15,2015$.

[20] Bandyopadhyay, N., Saha, A.K., A Comparative Analysis of Four Drought Indices Using Geospatial Data in Gujarat, India. Arabian Journal of Geosciences, 9(5), 2016.

[21] T.C. Tarım ve Orman Bakanlığı, Su Yönetimi Genel Müdürlüğü, Ulusal Kuraklık Yönetimi Strateji Belgesi ve Eylem Planı, 2017-2023.

[22] Şener, E., Şener, Ş., Meteorolojik Kuraklığın Coğrafi Bilgi Sistemleri Tabanlı Zamansal ve Konumsal Analizi: Çorak Gölü Havzası (Burdur-Türkiye) Örneği. Mühendislik Bilimleri ve Tasarım Dergisi, 7(3), 596-607, 2019.

[23] Önöz, B., Oğuz, B., İstanbul Su Temini Sistemi Ve Kuraklık Analizi. Teknik Dergi, 1083-1090, 1996.

[24] Kömüşcü, A.Ü., Using the Spi to Analyze Spatial and Temporal Patterns of Drought in Turkey. Vol. 11. 1999. 
[25] Türkeş, M., Tatlı, H., Use of the Standardized Precipitation Index (Spi) and a Modified Spi for Shaping the Drought Probabilities over Turkey. International Journal of Climatology, 29(15), 2270-2282, 2009.

[26] Sırdaş, S., Şen, Z., Meteorolojik Kuraklık Modellemesi ve Türkiye Uygulaması. İTÜ Mühendislik Dergisi, 2(2), 95-103, 2003.

[27] Bacanli, Ü.G., Dikbaş, F., Baran, T., Meteorological Drought Analysis Case Study: Central Anatolia. Desalination and Water Treatment, 26(1-3), 14-23, 2011.

[28] Karabulut, M., Drought Analysis in Antakya-Kahramanmaraş Graben, Turkey. Journal of Arid Land, 7(6), 741-754, 2015.

[29] Bulut, B., Yilmaz, M.T., Analysis of the 2007 and 2013 Droughts in Turkey by Noah Hydrological Model. Teknik Dergi/Technical Journal of Turkish Chamber of Civil Engineers, 27(4), 7619-7634, 2016.

[30] Güner Bacanli, Ü., Trend Analysis of Precipitation and Drought in the Aegean Region, Turkey. Meteorological Applications, 24(2), 239-249, 2017.

[31] Dabanlı, İ., Mishra, A.K., Şen, Z., Long-Term Spatio-Temporal Drought Variability in Turkey. Journal of Hydrology, 552, 779-792, 2017.

[32] Sönmez, F.K., Kömüscü, A.Ü., Erkan, A., Turgu, E., An Analysis of Spatial and Temporal Dimension of Drought Vulnerability in Turkey Using the Standardized Precipitation Index. Natural Hazards, 35, 243-264, 2005.

[33] Kadığlu M., Türkiye'de İklim Değişikliği Risk Yönetimi, Türkiye'nin İklim Değişikliği II. Ulusal Bildiriminin Hazırlanması Projesi Yayını, 172 sf., 2012.

[34] Dikbas, F., A Novel Two-Dimensional Correlation Coefficient for Assessing Associations in Time Series Data. International Journal of Climatology, 37(11), 40654076, 2017.

[35] Sensoy, S., Demircan, M., Ulupınar, Y., Climate of Turkey. Turkish State Meteorological Service.

[36] Erinç, S., Applied Climatology and the Climate of Turkey (in Turkish). 1957, Istanbul Technical University, Hydrogeology Institute: Istanbul, Turkey.

[37] Bacanli, U.G., Entropy Based Assessment and Palmer Drought Severity Index of Drought Analysis. Scientific Research and Essays, 7(44), 3823-3833, 2012.

[38] Zhang, Y., Cai, W., Chen, Q., Yao, Y., Liu, K., Analysis of Changes in Precipitation and Drought in Aksu River Basin, Northwest China. Vol. 2015. 2015. 1-15.

[39] Tsakiris, G., \& Vangelis, H. Towards a drought watch system based on spatial SPI. Water Resources Management, 18(1):1-12, 2004.

[40] Dikbas, F., A New Two-Dimensional Rank Correlation Coefficient. Water Resour Manage, 32(5), 1539-1553, 2018. 


\section{Appendix}

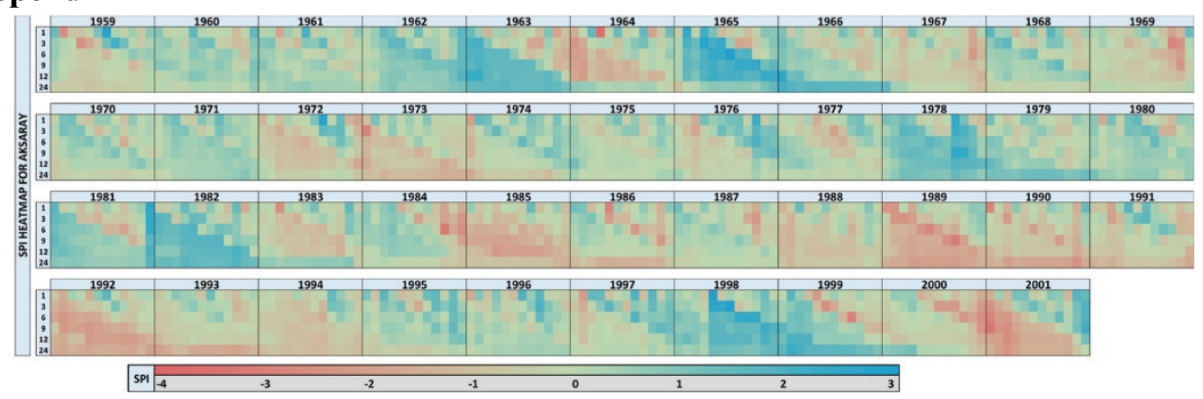

Figure A1 - Heatmap of the 1, 3, 6, 9, 12 and 24 month SPI series for the Aksaray station

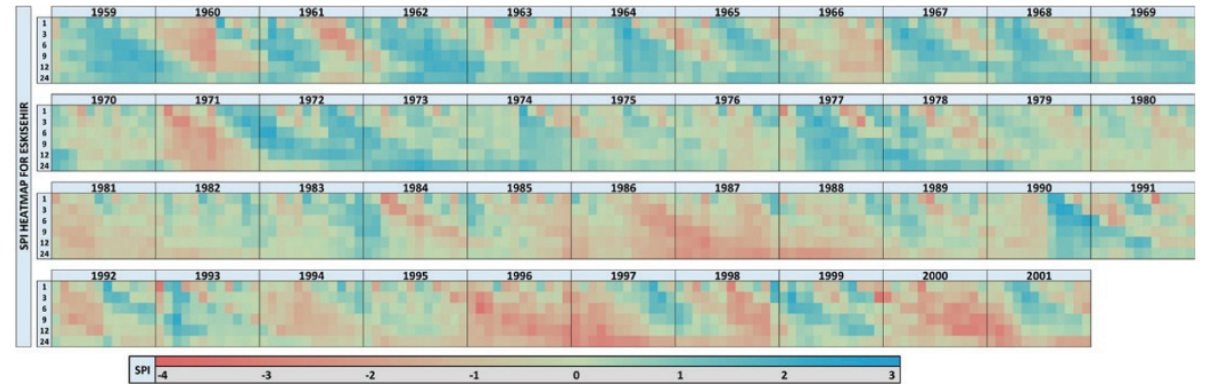

Figure A2 - Heatmap of the 1, 3, 6, 9, 12 and 24 month SPI series for the Eskişehir station

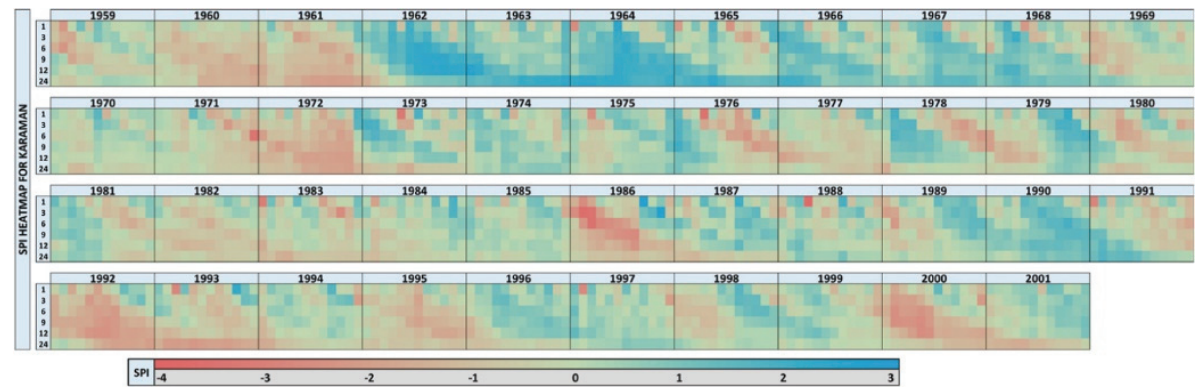

Figure A3 - Heatmap of the 1, 3, 6, 9, 12 and 24 month SPI series for the Karaman station

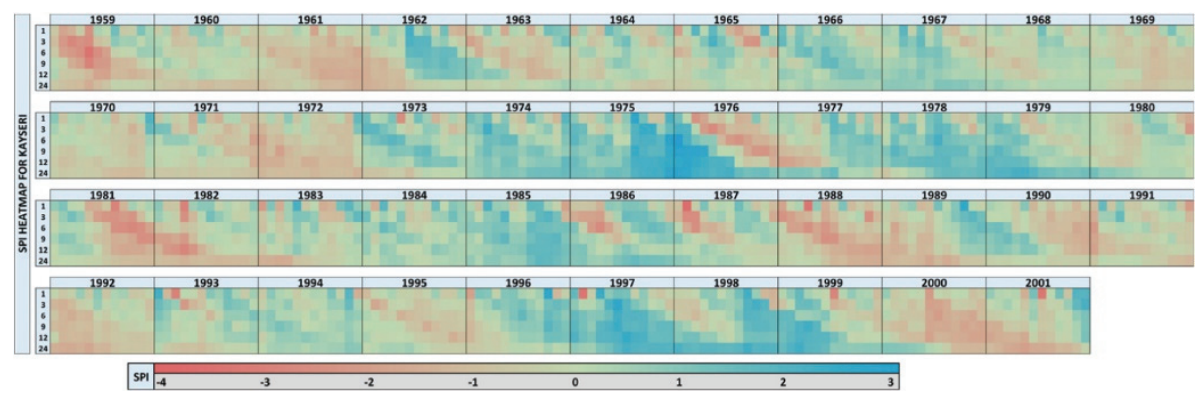

Figure A4 - Heatmap of the 1, 3, 6, 9, 12 and 24 month SPI series for the Kayseri station 
Detecting Drought Variability by using Two-Dimensional Correlation Analysis

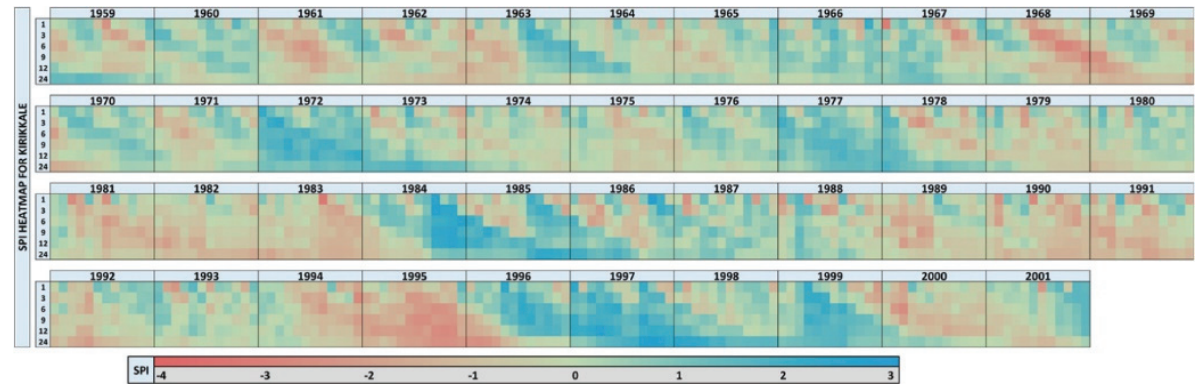

Figure A5 - Heatmap of the 1, 3, 6, 9, 12 and 24 month SPI series for the Kurtkkale station

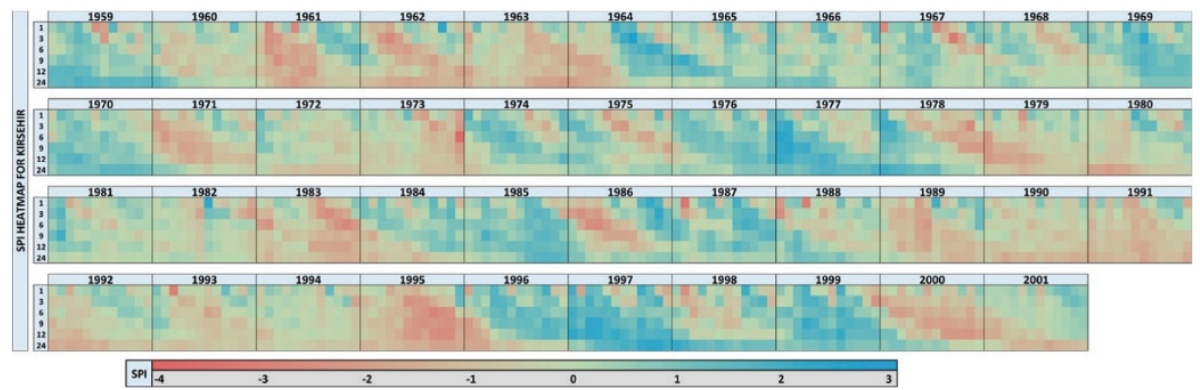

Figure A6 - Heatmap of the 1, 3, 6, 9, 12 and 24 month SPI series for the Kırşehir station

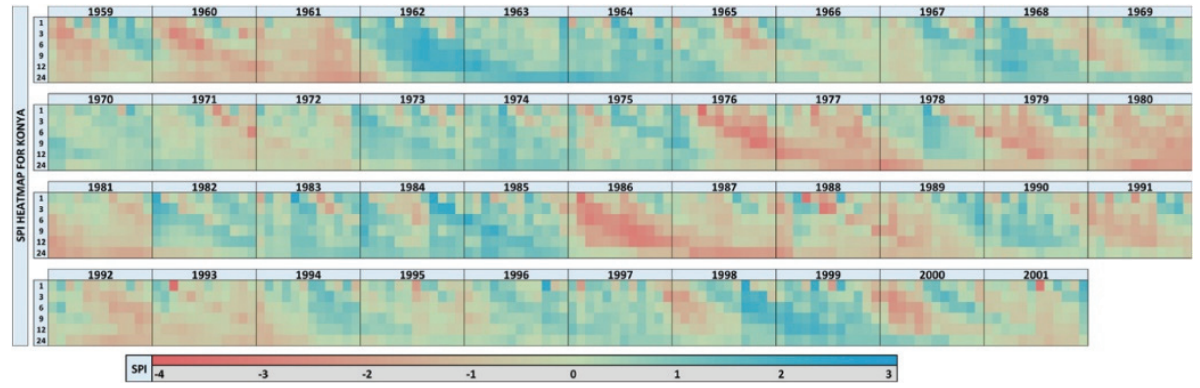

Figure A7 - Heatmap of the 1, 3, 6, 9, 12 and 24 month SPI series for the Konya station

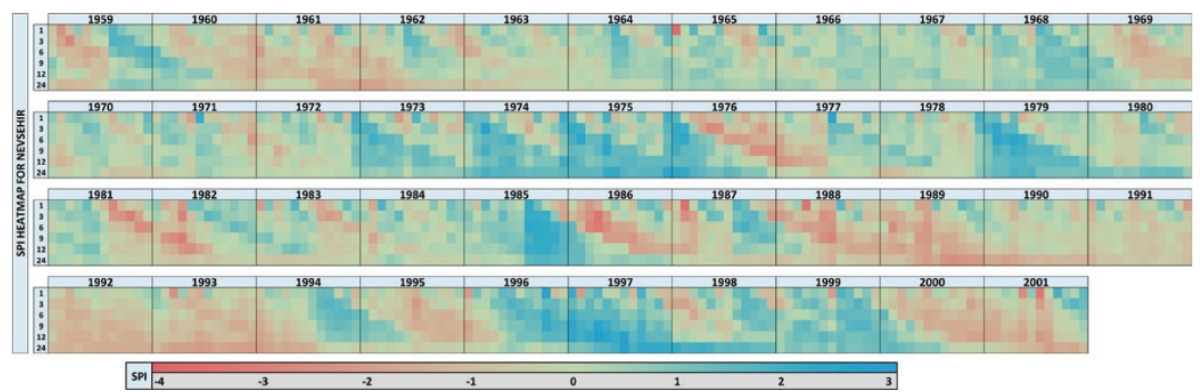

Figure A8 - Heatmap of the 1, 3, 6, 9, 12 and 24 month SPI series for the Nevşehir station 


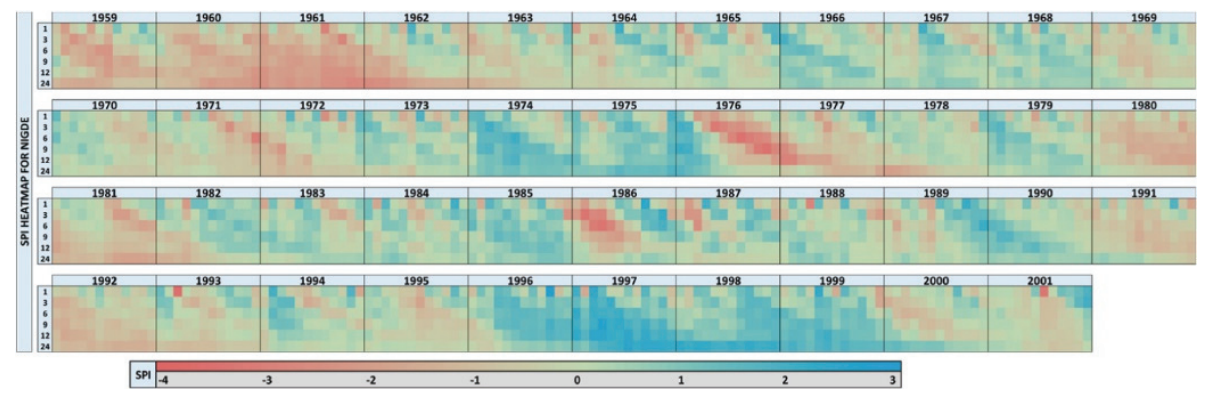

Figure A9 - Heatmap of the 1, 3, 6, 9, 12 and 24 month SPI series for the Niğde station

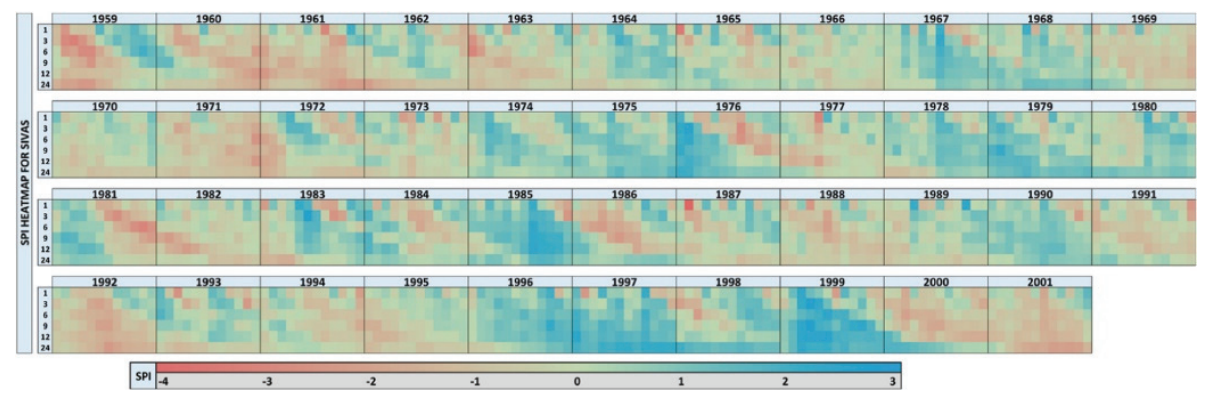

Figure A10 - Heatmap of the 1, 3, 6, 9, 12 and 24 month SPI series for the Sivas station

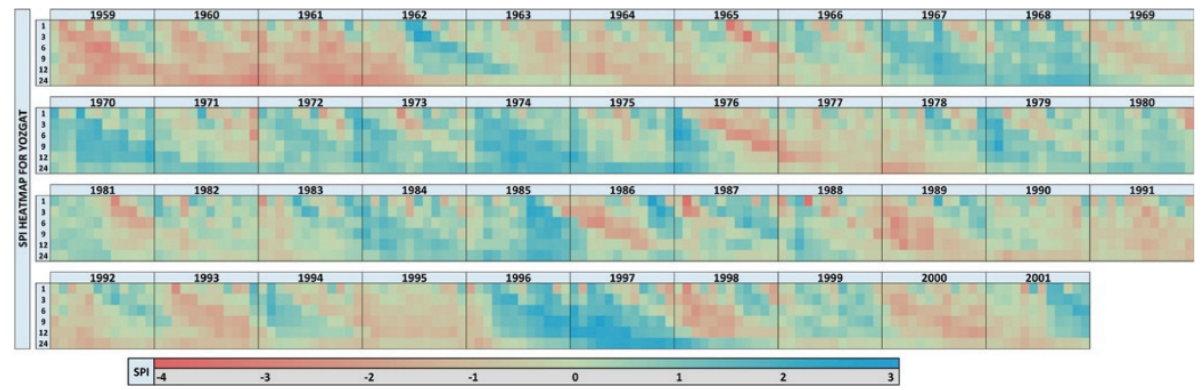

Figure A11 - Heatmap of the 1, 3, 6, 9, 12 and 24 month SPI series for the Yozgat station 
